\title{
Fusarium Head Blight Inoculum: Species Prevalence and Gibberella zeae Spore Type
}

\author{
S. G. Markell, Department of Plant Pathology, University of Arkansas, Fayetteville 72701, and L. J. Francl, De- \\ partment of Plant Pathology, The Pennsylvania State University, University Park 16802
}

\begin{abstract}
Markell, S. G., and Francl, L. J. 2003. Fusarium head blight inoculum: Species prevalence and Gibberella zeae spore type. Plant Dis. 87:814-820.

The objectives of this study were to examine the relative abundance of Gibberella zeae ascospores and conidia and other Fusarium species on wheat spikes in a field environment, to relate inoculum counts of $G$. zeae to airborne spore counts, and to evaluate an inoculum bioassay technique. The inoculum levels of Fusarium species and airborne spores of G. zeae were measured in North Dakota during the 1999, 2000, and 2001 growing seasons. Spores were collected from wheat spikes in a 24-h potted-plant bioassay in a fallowed field and in a spring wheat plot bioassay. Inoculum levels of Fusarium species were assessed by placing a solution recovered from bioassays on selective medium; meanwhile, ascospores and conidia of G. zeae were enumerated microscopically. A Burkard cyclonic sampler measured airborne spore levels in the fallowed field. Wheat spikes were inoculated with known concentrations of conidia or ascospores, and rinsate was put on selective medium at different intervals to compare recovery rates. Known concentrations of both spore types were also applied directly to selective medium to compare with recovery of spore types from inoculated spikes. Fusarium graminearum was the most prevalent Fusarium species on wheat spikes, although $F$. moniliforme and F. poae counts were highest on some days. Approximately twice as many ascospores were recovered in both the 24-h potted-plant field bioassay and the cyclonic sampler as were conidia. Significantly more colonies were recovered from wheat spikes after conidial inoculation than after ascospore inoculation at an identical concentration regardless of time of rinsate collection. Colony numbers did not differ significantly following application of ascospores and conidia to selective medium. Results confirm the predominance of G. zeae inoculum in North America but indicate conidia play an important role in the primary disease cycle.
\end{abstract}

Additional keywords: epidemiology, scab

Fusarium head blight (scab) of wheat and barley is caused primarily by the pathogen Gibberella zeae (Schwein.) Petch (anamorph: Fusarium graminearum) in North America $(1,8,17)$. Fusarium sporotrichioides, F. equiseti, F. moniliforme, and other Fusarium species can cause head blight also but are less able to do so than G. zeae (16). Crop debris, particularly cereal stubble, gives rise to inoculum in the form of ascospores and conidia when colonized by $G$. zeae $(3,17,19,21)$. Prevalence of airborne ascospores has been linked to such factors as rainfall and humidity $(4,11,13)$. Given the appropriate environmental conditions for inoculum dispersal and disease development, an outbreak can

Corresponding author: S. Markell

E-mail: SMarkel@uark.edu

This research was supported in part by a grant through the U.S. Wheat and Barley Scab Initiative to North Dakota State University, USDA-ARS grant number 59-0790-9-035.

Accepted for publication 4 February 2003.

Publication no. D-2003-0428-03R

(c) 2003 The American Phytopathological Society decimate a crop $(1,8,17)$. Although ascospores and conidia are equally infective (15), at least one study found many fewer conidia present in airborne samples taken over an infected corn-kernel inoculated field, suggesting that ascospores exerted greater disease pressure on the host than conidia (4).

A bioassay has been used by researchers to assess the relative abundance of Fusarium species on wheat spikes in multiple growing regions (5). Although results have been published using the technique, the relative adherence of conidia and ascospores to the wheat spikes has not yet been examined; moreover, spore recovery relative to time after inoculation has not been studied. In another study (S. Markell and L. Francl, unpublished), ascospore levels collected from a Burkard volumetric sampler have not corresponded well to inoculum levels collected from the aforementioned bioassay. This disparity suggests that conidia may play a larger role in Fusarium head blight epidemics than previously thought.

The goals of this research were to assess the abundance of Fusarium species present on wheat spikes exposed to field conditions, evaluate the recovery efficiency of the inoculum bioassay, and determine the relative contribution of conidia and ascospores as potential inoculum sources. In addition, a preliminary analysis was conducted for the relationship between environmental variables and inoculum levels.

\section{MATERIALS AND METHODS}

Field inoculum. Research to obtain relative levels of Fusarium species on wheat spikes was conducted at the North Dakota State University Experiment Station in Fargo. The hard red spring wheat cultivar Norm (susceptible to Fusarium head blight) was planted on wheat straw left from the previous growing season. The period in which spikes were in anthesis was extended by multiple planting dates in a randomized complete block design replicated three times. In 1999, Norm was planted on 29 April, and 19 and 24 May; in 2000, plantings were on 25 April, and 3 and 10 May; and in 2001, plantings were on 3, 14, and 25 May. Treatment 1 from the first planting date was covered with clear plastic to speed seedling growth (10), while treatments 2,3 , and 4 (one treatment from each planting date) were left uncovered. As wheat emerged, plastic was cut to allow for air and moisture exchange. Each of the 12 blocks measured $12.2 \times 1.2 \mathrm{~m}$ and was surrounded by a $1.2-\mathrm{m}$ fallow border.

Although wheat straw from a Fusarium head blight-susceptible cultivar served as a base inoculum reservoir in all years, artificial inoculum was added in 2000 to compensate for low disease intensity in the 1999 season. To prepare the inoculum, a hyphal tip of G. zeae field isolate Hagar94 was transferred to half-strength potato dextrose agar (PDA) in a $100 \times 15 \mathrm{~mm}$ petri plate and allowed to grow 1 week. Stainless steel cake pans measuring $23 \times$ $33 \times 8 \mathrm{~cm}$ were filled nearly half full with corn kernels and $600 \mathrm{ml}$ of distilled water. Kernels were allowed to soak overnight and then were autoclaved for $3 \mathrm{~h}$. The colonized agar was blended in $500 \mathrm{ml}$ of sterile distilled water and aseptically mixed with the corn kernels. Cake pans were kept covered in a growth chamber at $22^{\circ} \mathrm{C}$. The mixture was stirred aseptically after 1 week and incubated two more weeks. Corn kernels were spread on plots and interior border rows at a rate of $10 \mathrm{~g} / \mathrm{m}^{2}$ at stem elongation, Zadoks 30 to 35 (22).

The plots were sampled daily at $1000 \mathrm{~h}$ between heading and early milk, Zadoks 
58 to 72 . Five spikes from each replication were clipped and placed in a solution of 50 $\mathrm{ml}$ of sterile distilled water and 1 drop of Tween 20 surfactant. The solution was shaken vigorously for $2 \mathrm{~min}$, decanted, and frozen at $-80^{\circ} \mathrm{C}$ until later assessment.

Inoculum levels were similarly assayed on potted Norm wheat plants, which had been grown in the greenhouse and then isolated in a growth chamber for 1 week before heading. Once in anthesis, three pots of Norm were transferred to a fallow field environment with pots spaced approximately $25 \mathrm{~m}$ apart in a line. One pot of Norm was left in the growth chamber as a control. Pots were transferred between 0730 and $0800 \mathrm{~h}$ and remained in the fallowed field for a $24-\mathrm{h}$ period. The 3,500 $\mathrm{m}^{2}$ fallow field contained wheat stubble from the previous year's crop and, in 2000 only, stubble plus corn kernel inoculum that was spread at $8.2 \mathrm{~g} / \mathrm{m}^{2}$. Upon collection from the field, four spikes from each pot were clipped immediately and placed in an autoclaved solution of $40 \mathrm{ml}$ of distilled water and 1 drop of Tween 20 . The solution was shaken vigorously for $2 \mathrm{~min}$, decanted, and frozen until later assessment. The study ran from days 177 to 202,172 to 200, and 168 to 194 in 1999, 2000, and 2001, respectively.

To determine species abundance, a 0.5$\mathrm{ml}$ aliquot of thawed solution was transferred under sterile conditions to Komada's medium, an antibiotic, Fusarium-selective medium (2). Cultures were grown at room temperature and under light conditions according to Tschanz et al. (18). After 1 week, colonies were categorized by color and type of growth. Sample colonies of each type were transferred to half-strength potato dextrose agar (PDA), carrot agar, and/or carnation leaf agar for identification of Fusarium species $(2,9)$. The number of colonies identified in each specific category was multiplied by the percentage of colonies in each category to derive the population levels of each Fusarium species.

Environmental conditions were recorded every 30 min with an automatic weather station (Campbell Scientific model CR10X, Provo, UT) in a field adjacent to the aforementioned field plots. Sensors monitored surface wetness as electrical resistance (kilo-ohms) at the canopy; relative humidity (percent) and temperature (degrees Celsius) at $2 \mathrm{~m}$; and rainfall $(\mathrm{mm})$, solar radiation $\left(\mathrm{KJ} / \mathrm{m}^{2} \mathrm{~s}\right)$, wind speed $(\mathrm{m} / \mathrm{s})$, and wind direction (degrees) at $3 \mathrm{~m}$. Inoculum levels and environmental summaries for a 24-h and an 8-h period before assay were correlated using the Minitab statistical program (Minitab, Inc. Release 12, State College, PA).

G. zeae spore type recovery. To compare ascospores and conidia recovered on the 24-h potted-plant bioassay, $10 \mathrm{ml}$ of the solution from each pot was centrifuged for $15 \mathrm{~min}$ at $5,000 \mathrm{rpm}$. Nine milliliters of supernatant was decanted, and the three remaining 1-ml samples were combined for each day (the control excluded) to create a daily sample. The daily sample was centrifuged again for $15 \mathrm{~min}$ at 5,000 rpm and the top $2 \mathrm{ml}$ of solution decanted. If the colony forming units (CFU) for that day were found to be in the top $20 \%$ of all assayed days, the remaining solution was observed microscopically to count $G$. zeae conidia and ascospores. Conidia and ascospores were tabulated from a $15-\mu l$ aliquot placed on a microscope slide and scanned in parallel fields. Scanning stopped when either fields equivalent to $12 \mu \mathrm{l}$ had been viewed, or more than 12 spores had been observed. Sixteen days were examined.

Airborne spores were also sampled in 2001 with a Burkard cyclonic spore sampler (Rickmansworth, UK) at the same field site as the 24-h bioassays. The volume of air sampled was approximately 1 $\mathrm{m}^{3} / \mathrm{h}$ in 19 - to $74-\mathrm{h}$ intervals. Sample collection followed the protocol of Larson et al. (7), which resulted in a final volume of $1 \mathrm{ml}$. Three 15- $\mu \mathrm{l}$ drops of the sample were placed on a microscope slide, and conidia and ascospores were tabulated. Samples were collected from day 171 to day 212 in 2001.

Evaluation of bioassay: G. zeae spore type recovery. Adherence of G. zeae ascospores and conidia from wheat spikes was analyzed by direct inoculation of wheat spikes at mid-anthesis (Zadoks 65) with a known amount of each spore type. Inocula of ascospores and conidia were obtained from $G$. zeae field isolate Hagar94. Conidia and ascospores were produced on carnation leaf agar. Conidia were harvested from a 7- to 10-day-old culture and frozen until inoculation. Ascospores were harvested from the petri dish lid of a 7- to 10day-old culture. Inoculum levels of 250 ascospores per spike, 250 conidia per spike, or water were applied to the wheat spikes with a paint spray gun (Badger Basic model 250, Franklin Park, IL) in an encasement designed to eliminate external air disturbance and ensure constant application levels. Clipped spikes were then placed in a moist incubator with their peduncles in water. Conidia-inoculated, ascospore-inoculated, and water-inoculated (control) spikes were sampled separately in groups of four at intervals of $0.5,3,7$, and $24 \mathrm{~h}$ after inoculation using the field sampling protocol described above. Three repetitions of this experiment were performed.

A $0.5-\mathrm{ml}$ aliquot of solution was transferred under sterile conditions to Komada's selective medium and incubated at $22^{\circ} \mathrm{C}$. Colonies were counted, and comparisons were made among time intervals and spore type. A $t$ test and linear regression were used to analyze results. To compare recovery of conidia and ascospores, three plates of Komada's medium were directly inoculated with $25,50,100$, or 250 conidia or ascospores and allowed to grow as de- scribed above. Three replications were performed.

\section{RESULTS}

Fusarium head blight occurred in the experimental fields in 1998, 1999, 2000, and 2001. Spring wheat planted in 1998 had a final disease severity of $21 \%$. In 1999, disease severity in Grandin and Norm fields adjacent to the research plots was 6 and $1.3 \%$, respectively. Grandin field severity in 2000 was approximately $7 \%$ and was less than $1 \%$ in 2001.

Field samples. Of the seven Fusarium species observed on the 24-h potted-plant bioassay in 1999, F. graminearum was the most prevalent species throughout the study (Fig. 1). F. equiseti and F. sporotrichioides were observed during the entire period, and $F$. sporotrichioides became most frequent late in the study, about the same time daily levels of $F$. graminearum declined (results not shown). F. moniliforme, $F$. semitectum, $F$. culmorum, and $F$. sambucinum were found sporadically in low numbers (Fig. 1). No Fusarium species were recovered from control spikes except for F. moniliforme on one occasion.

Treatments 1 and 4 were not sampled in 1999 due to unfavorable wheat growth. Three different Fusarium species were commonly recovered from treatments 2 and 3 in the Norm field plots (Fig. 1). F. graminearum was the dominant species in both plots, followed closely by $F$. sporotrichioides. F. equiseti was consistently recovered but in less frequency than either of the other two species.

$F$. graminearum and $F$. moniliforme were the most common of seven species recovered on the 24-h potted-plant bioassay throughout 2000 (Fig. 1). F. graminearum was less common than both $F$. sporotrichioides and $F$. equiseti in the beginning of the study, but became predominant as the period progressed. Recovery of both $F$. equiseti and $F$. moniliforme remained moderate to high until the latter part of the study when observations of both species became less frequent. F. sporotrichioides, F. semitectum, F. sambucinum, and $F$. poae were observed at low levels throughout the study. F. moniliforme was recovered from control plants twice during the study.

Seven different Fusarium species were also recovered from the field plots in 2000 (Fig. 1). Low levels of all species were observed in treatments 3 and 4, and data were not analyzed further. Treatments 1 and 2 reached anthesis simultaneously, so collections of sample dates overlapped (Fig. 2). The highest counts of G. zeae inoculum were recovered from both plots on days 179 and 183, contradicting what was recovered during the 24-h bioassay (Fig. 2). F. sporotrichioides, F. equiseti, and $F$. moniliforme were all observed frequently throughout the study in moderately low levels (Fig. 1). Low levels of F. sam- 
bucinum, $F$. chlamydosporum, and $F$. avenaceum were also observed.

$F$. graminearum was the most frequently isolated Fusarium species for the 24-h potted-plant bioassays in 2001. F. sporotrichioides, $F$. moniliforme, and $F$. equiseti were found in moderate amounts throughout the study (Fig. 1). The highest levels of $F$. graminearum recovered throughout the 3-year study were found in 2001 (Fig. 2).

Time of maturation differed among treatments 2, 3, and 4 in 2001, which re- sulted in a 24-day continual sampling window in the wheat plots (Fig. 2). The only high inoculum levels recovered from treatment 2 were of $F$. graminearum in the first few days it was sampled; all species levels were low after that. High levels of $F$.
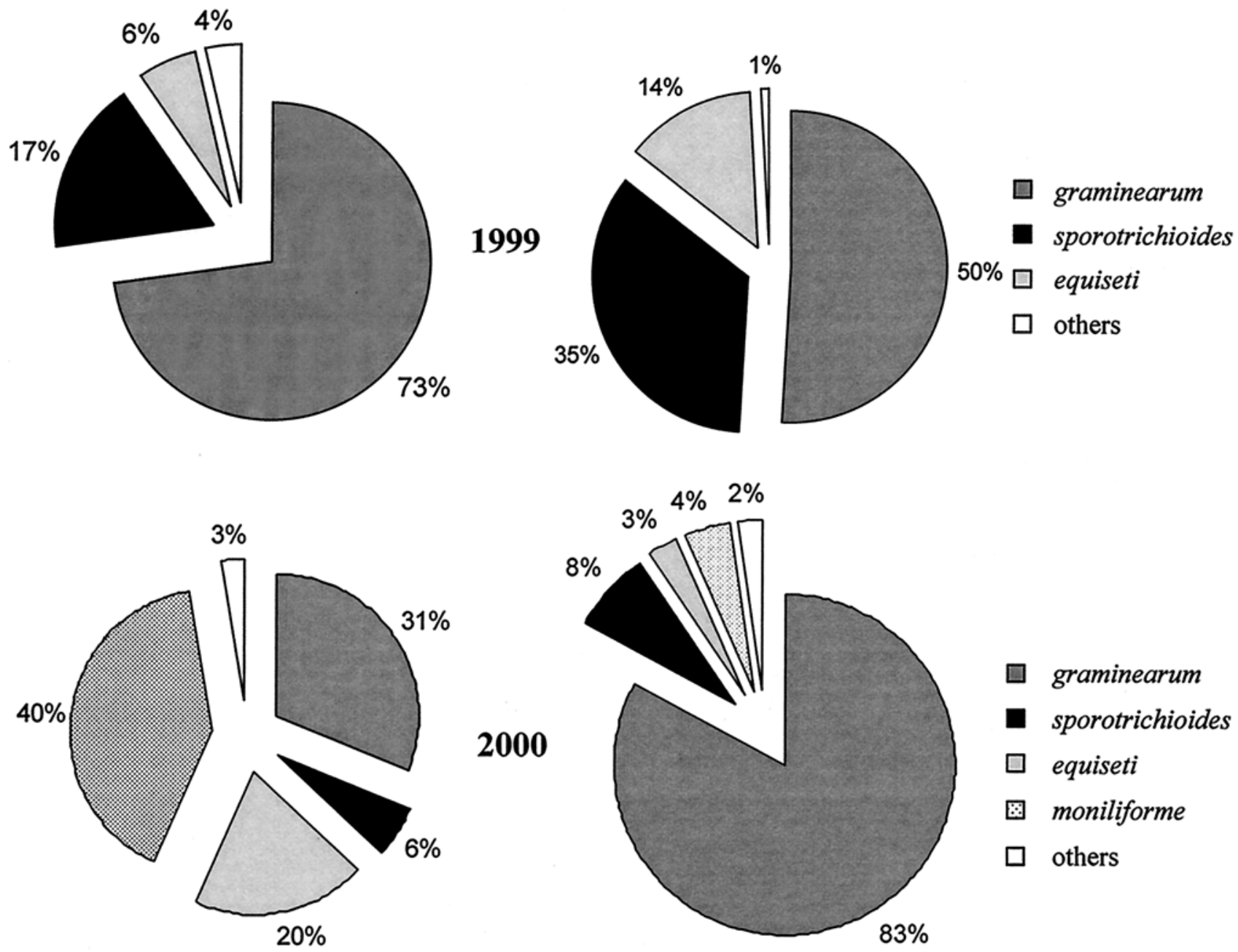

$\square$ graminearum

- sporotrichioides

$\square$ equiseti

moniliforme

$\square$ others
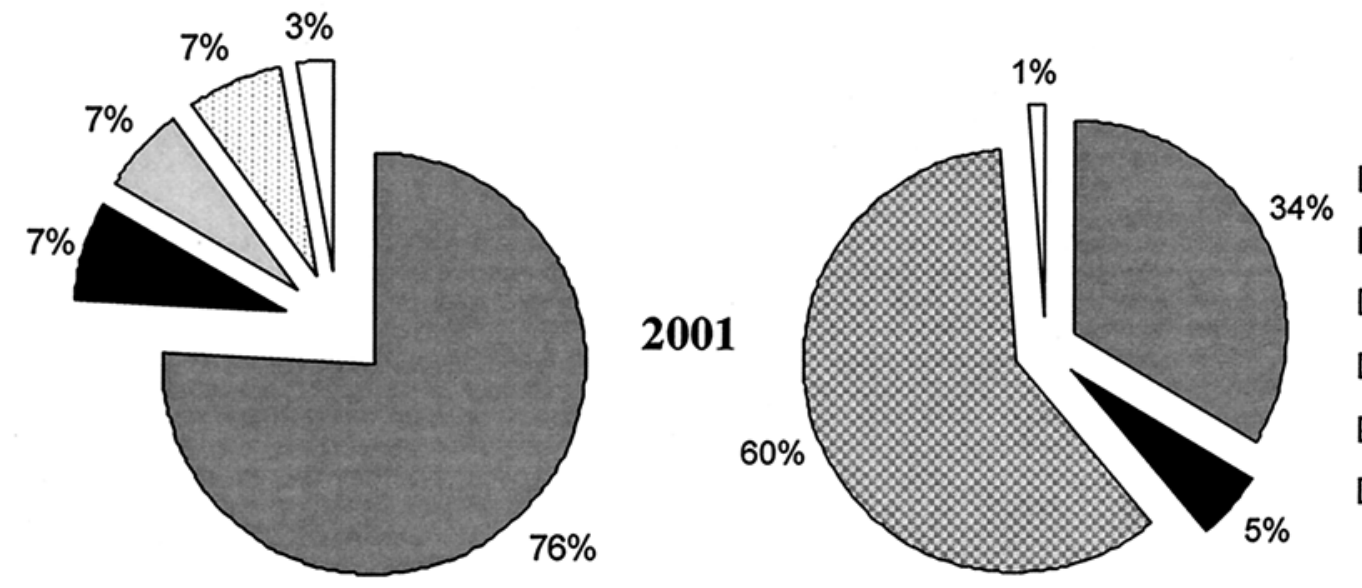

graminearum sporotrichioides

$\square$ equisetti

回 $p_{\text {oae* }}^{*}$

๑ moniliforme

others

\section{Hour Potted Plant Bioassay}

*All F. poae in the $200124 \mathrm{~h}$ bioassay was recovered on only two days in the study

Fig. 1. Percent abundance of Fusarium species by year on wheat spikes in a 24-h potted-plant bioassay and the combined field plot bioassays. 
graminearum appeared on the last few days sampled in treatment 4 . Very high levels of $F$. poae occurring during 2 days of collection (day 201 and day 203) accounted for $60 \%$ of all Fusarium species recovered during the entire study (Fig. 1).
Inoculum recovery and environment. Environmental conditions were not correlated with daily $G$. zeae inoculum levels (potted plants) in any of the years of the study. Multiple regression analysis found no significant relationship between $G$. zeae inoculum levels and 24-h environmental summaries in any of the years. Regression between environmental conditions during the last $8 \mathrm{~h}$ of each 24-h potted-plant bioassay and inoculum levels revealed no significant association.
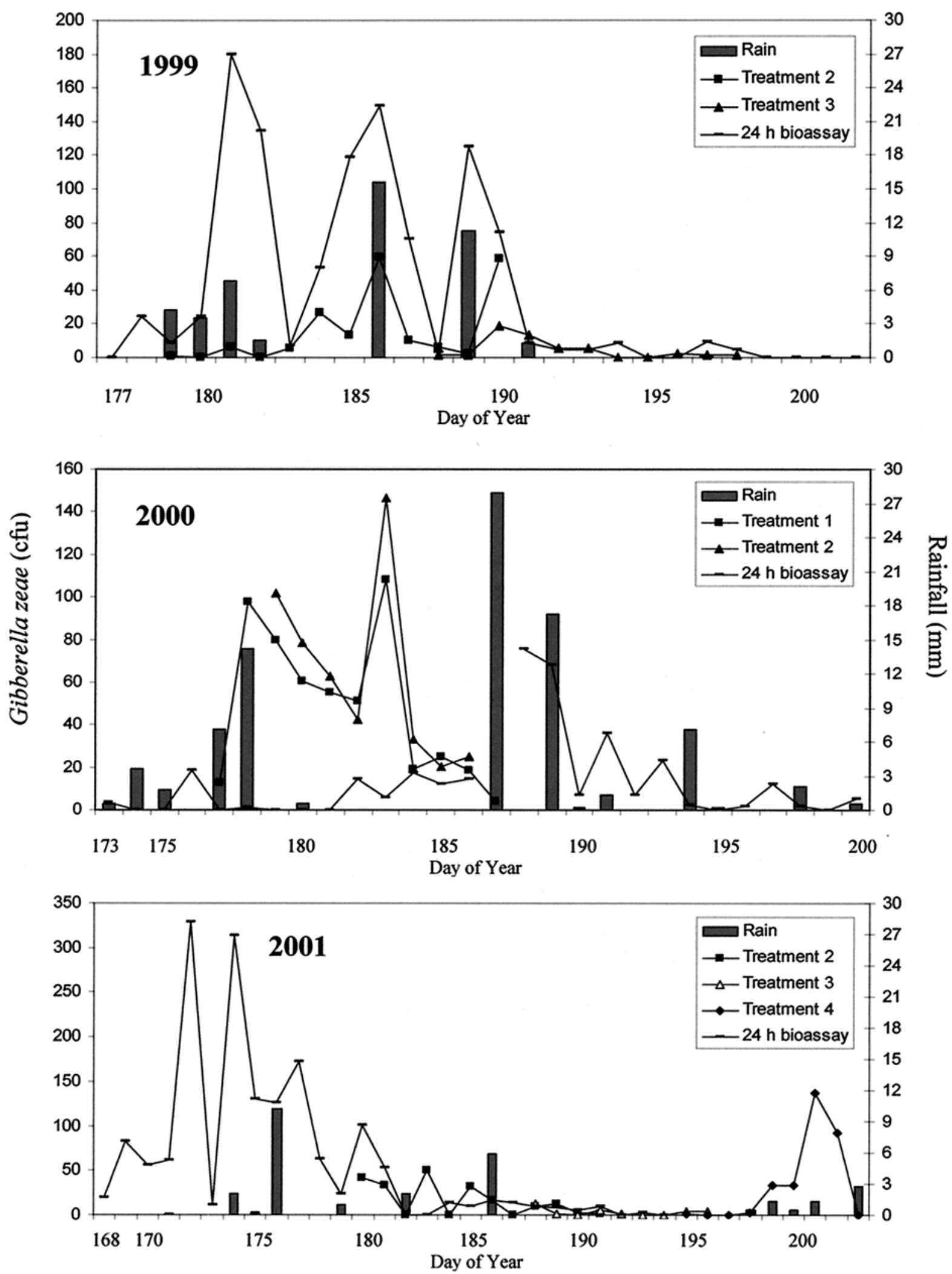

Fig. 2. Daily levels of Fusarium graminearum colony forming units (CFU) recovered from wheat spikes in a 24-h potted-plant bioassay and field plot bioassays and millimeters of rainfall in 1999, 2000, and 2001 field studies. 
Rainfall frequency was similar in all years, with at least trace amounts of rainfall recorded on 31,38 , and $37 \%$ of the days in 1999, 2000, and 2001, respectively. However, rainfall amounts were highest in 2000. Five days with $6 \mathrm{~mm}$ or more of rain were observed in 2000, while only 3 and 2 days in 1999 and 2001, respectively, recorded rain periods higher than $6 \mathrm{~mm}$ (Fig. 2).

G. zeae spore type recovery. A daily fluctuation in the spore type ratio was found when the 24-h potted-plant rinsates were enumerated microscopically (Table 1). Both spore types were observed on all days with five exceptions: day 190 in 1999 when neither spore type was found, and days 174 to 177 in 2001, when only ascospores were observed. When both spore types were recovered, the composition of inoculum per sample varied from 40 to $90 \%$ ascospores, with an average of approximately two ascospores to every one conidium.

Of the 108 spores collected by the Burkard volumetric spore sampler that were identified microscopically in 2001, 62 were ascospores (Table 2). The time series was characterized by several high spore counts, consisting of both ascospores and conidia, over relatively short time periods; for instance, in three separate 26hour or less sampling periods, 12, 13, and 14 spores were recovered.

Significantly more CFU, at all postinoculation time intervals, were recovered from Norm wheat spikes when inoculated with conidia than when inoculated with ascospores (Table 3). CFU recovered from direct application of ascospores and conidia to Komada's medium were not significantly different based on a two sample $t$ test comparing each concentration separately (Table 4).

\section{DISCUSSION}

Our results agree with surveys of wheat and barley in the northern prairie regions of the United States and Canada that identified $F$. graminearum as the dominant species causing Fusarium head blight $(1,4,6,14,20)$. Temporal fluctuation in levels of all Fusarium species were observed in each of the 3 years, suggesting that some less pathogenic species could influence disease intensity outcome, either alone or through an interaction with $F$. graminearum.
Inoculum levels coincided among collected samples from treatments that overlapped (Fig. 2). In 2000, when all collection days of treatments 1 and 2 overlapped, a strong relationship was observed between both $F$. graminearum (Fig. 2) and $F$. sporotrichioides (results not shown). Inoculum levels were also in agreement during three overlapping days in 1999. The consistent

Table 2. Gibberella zeae ascospores and conidia observed microscopically in samples collected from a Burkard volumetric spore sampler in 2001

\begin{tabular}{|c|c|c|c|c|}
\hline \multicolumn{2}{|c|}{ Sample period } & \multirow[b]{2}{*}{ Time (h) } & \multirow[b]{2}{*}{ Ascospores } & \multirow[b]{2}{*}{ Conidia } \\
\hline Start (day) & End (day) & & & \\
\hline 171 & 172 & 27 & 2 & 0 \\
\hline 172 & 173 & 22 & 0 & 0 \\
\hline 173 & 174 & 29 & 0 & 0 \\
\hline 174 & 175 & 24 & 0 & 0 \\
\hline 175 & 176 & 24 & 2 & 3 \\
\hline 176 & 177 & 24 & 12 & 2 \\
\hline 177 & 178 & 28 & 3 & 0 \\
\hline 178 & 179 & 23 & 0 & 0 \\
\hline 179 & 180 & 24 & 2 & 1 \\
\hline 180 & 181 & 20 & 5 & 0 \\
\hline 181 & 183 & 51 & 0 & 0 \\
\hline 183 & 184 & 26 & 0 & 0 \\
\hline 184 & 186 & 46 & 0 & 0 \\
\hline 186 & 187 & 26 & 0 & 2 \\
\hline 187 & 188 & 19 & 0 & 0 \\
\hline 188 & 189 & 24 & 0 & 0 \\
\hline 189 & 190 & 27 & 0 & 0 \\
\hline 190 & 191 & 24 & 0 & 0 \\
\hline 191 & 192 & 24 & 0 & 0 \\
\hline 192 & 193 & 24 & 0 & 0 \\
\hline 193 & 194 & 25 & 0 & 0 \\
\hline 194 & 195 & 20 & Sample lost & \\
\hline 195 & 197 & 52 & 3 & 1 \\
\hline 197 & 198 & 24 & 0 & 0 \\
\hline 198 & 199 & 24 & 10 & 3 \\
\hline 199 & 200 & 25 & 1 & 4 \\
\hline 200 & 201 & 24 & 1 & 1 \\
\hline 201 & 204 & 72 & 9 & 3 \\
\hline 204 & 205 & 22 & 1 & 0 \\
\hline 205 & 206 & 23 & 1 & 0 \\
\hline 206 & 207 & 27 & 4 & 3 \\
\hline 207 & 208 & 20 & 1 & 0 \\
\hline 208 & 211 & 74 & 0 & 0 \\
\hline 211 & 212 & 26 & 5 & 7 \\
\hline Total & & 993 & 62 & 30 \\
\hline
\end{tabular}

Table 1. Gibberella zeae ascospores and conidia observed microscopically in samples of washed wheat spikes of the 24-h bioassay from a field environment

\begin{tabular}{|c|c|c|c|c|c|c|}
\hline & Day ${ }^{y}$ & Ascospores & Conidia & $\begin{array}{c}\text { Ascospores/ } \\
\text { Conidia }\end{array}$ & $\mu \mathrm{l}$ sampled & CFU/head $^{\mathrm{z}}$ \\
\hline \multirow[t]{8}{*}{1999} & 181 & 9 & 6 & 1.5 & 13.5 & 180 \\
\hline & 182 & 9 & 10 & 0.9 & 13.5 & 134 \\
\hline & 184 & 13 & 7 & 1.9 & 16.5 & 53.2 \\
\hline & 185 & 5 & 8 & 0.6 & 6 & 119 \\
\hline & 186 & 9 & 8 & 1.1 & 15 & 149 \\
\hline & 187 & 4 & 1 & 4 & 19.5 & 70 \\
\hline & 189 & 10 & 4 & 2.5 & 9 & 125 \\
\hline & 190 & 0 & 0 & 0 & 12 & 74 \\
\hline \multirow[t]{2}{*}{2000} & 188 & 4 & 1 & 4 & 12 & 75.6 \\
\hline & 189 & 17 & 5 & 3.4 & 12 & 67.9 \\
\hline \multirow[t]{6}{*}{2001} & 169 & 18 & 2 & 9 & 11 & 81.9 \\
\hline & 172 & 7 & 2 & 3.5 & 12 & 328.6 \\
\hline & 174 & 4 & 0 & NA & 13 & 314.0 \\
\hline & 175 & 3 & 0 & NA & 13 & 129.6 \\
\hline & 176 & 4 & 0 & NA & 13 & 126.0 \\
\hline & 177 & 5 & 0 & NA & 12 & 172.6 \\
\hline
\end{tabular}

y Plants were collected at 0800 on day of year listed.

${ }^{\mathrm{z}}$ Inoculum recovered on Komada's medium from potted plants. 
recovery of similar inoculum levels in overlapping assays supports the consistency of the technique.

Inoculum levels from the 24-h pottedplant bioassay were comparable to and supportive of data from other field experiments (4). Inoculum levels fluctuated considerably (Fig. 2) throughout the study. In 1999 and 2000, several high spikes in inoculum levels were recorded while wheat plants were in the most susceptible stages of growth (approximate anthesis days were 179 to 183 and 191 to 189 , respectively), while no such high inoculum levels were observed while plants were highly susceptible in 2001 (approximate anthesis days were 181 to 186). Although inoculum availability is only one component necessary for disease, our field severities during the 3 years of the study tended to mirror the presence of high inoculum levels during susceptible growth stages.

Generally, more CFU were recovered following rainfall events, but this was not a consistent phenomenon. For example, the 4 days in 1999 with the highest inoculum levels recovered from the potted-plant bioassay (days 181, 182, 186, and 189) had experienced rainfall within the last $24 \mathrm{~h}$, but rainfall had not occurred on days 184 , 185 , and 187, when relatively high levels of inoculum were observed (Fig. 2). Further study of the relationship between inoculum counts and environmental factors is necessary prior to use in disease forecasting.

In 2001, low inoculum levels while wheat was in susceptible growth stages was likely a consequence of a 168-mm rainfall on day 172 , immediately before the study began (not shown in Fig. 2). Both the corn kernel inoculum and natural wheat stubble were submerged or washed away in the week or more that the field was flooded.

Approximately twice as many ascospores as conidia were observed in the 24-

Table 3. Average recovery of Gibberella zeae ascospores and conidia from Norm wheat heads inoculated with equal numbers of spores at four different postinoculation times

\begin{tabular}{|c|c|c|c|c|c|c|}
\hline & \multicolumn{4}{|c|}{ CFU/head } & \multicolumn{2}{|c|}{ Regression } \\
\hline & $0.5 \mathrm{~h}$ & $3 \mathrm{~h}$ & $7 \mathrm{~h}$ & $24 \mathrm{~h}$ & Slope & Linear fit \\
\hline Conidia/head & $153.33 \mathrm{a}^{\mathrm{z}}$ & $120 \mathrm{a}$ & $120 \mathrm{a}$ & $33.33 \mathrm{a}$ & -0.139 & Yes \\
\hline Ascospores/head & $26.67 \mathrm{~b}$ & $40 \mathrm{~b}$ & $46.67 \mathrm{~b}$ & $13.33 \mathrm{~b}$ & -0.714 & No \\
\hline Conidia/ascospore & 5.75 & 3 & 2.57 & 2.5 & & \\
\hline
\end{tabular}

${ }^{\mathrm{z}}$ Numbers within a column followed by the same letter are not significantly different according to a $t$ test with $\alpha=0.05$.

Table 4. Average number of colony forming units (CFU) recovered on Komada's medium when known quantities of Gibberella zeae ascospores and conidia were applied

\begin{tabular}{lccc}
\hline $\begin{array}{l}\text { Application rate } \\
\text { spores/plate }\end{array}$ & $\begin{array}{c}\text { Conidia }\left(\boldsymbol{\mu}_{\boldsymbol{1}}\right) \\
\text { CFU/plate }\end{array}$ & $\begin{array}{c}\text { Ascospore }\left(\boldsymbol{\mu}_{\mathbf{2}}\right) \\
\text { CFU/plate }\end{array}$ & $\begin{array}{c}\boldsymbol{P} \text { value }^{\mathbf{z}} \\
\left(\boldsymbol{\mu}_{\mathbf{1}}=\boldsymbol{\mu}_{\mathbf{2}}\right)\end{array}$ \\
\hline 25 & 10 & 5 & 0.21 \\
50 & 15 & 9 & 0.22 \\
100 & 35 & 21 & 0.08 \\
250 & 72 & 53 & 0.25 \\
\hline
\end{tabular}

${ }^{\mathrm{z}} P>0.05$ indicates no evidence of significant difference between spore types based on three replications. ratio for the cyclonic sampler solution. In contrast to this expectation, both samples recovered about two ascospores to one conidium (Tables 1 and 2).

One problem experienced on some days, particularly those when rain had occurred, was that it was often difficult to get a potted-plant bioassay sample clean, yet concentrated enough, to view either spore type. In some samples, so much dirt had been splashed on the wheat spikes that, although a high level of colonies were recovered on assayed spikes, few if any spores could be identified microscopically and therefore went uncounted. This was unfortunate, considering rainfall has been linked to high inoculum and disease levels $(4,8,13,17)$. Similar problems were noted when microscopically viewing samples of conidia and ascospores collected from the Burkard cyclonic spore sampler, although not nearly as severe. Despite being closer to the ground, the small cross-sectional surface area $\left(28 \mathrm{~mm}^{2}\right)$ of the air intake orifice may have limited the amount of unwanted material that entered the sample, unlike the wheat spike bioassay, which collected more unwanted material on its high surface area. However, we presume an equal chance of seeing conidia as ascospores for each collection method so the observed spore ratio should be unaffected.

Observation of both conidia and ascospores on wheat spikes and the implications for overall inoculum level and infection by each spore type are useful to understanding the dynamics of both the pathogen and the disease. Clearly, any attempt to manage head blight by focusing on inoculum will have to take both spore types into consideration. Further research concerning the source of conidia and their fate on wheat spikes will decipher more thoroughly the disease cycle of Fusarium head blight.

\section{ACKNOWLEDGMENTS}

We thank Shaukat Ali and Bacilio Salas for their time and expertise regarding Fusarium morphology and identity. Their contribution helped make this work possible.

\section{LITERATURE CITED}

1. Clear, R. M., and Patrick, S. K. 2000. Fusarium head blight pathogens isolated from fusarium-damaged kernels of wheat in western Canada, 1993 to 1998. Can. J. Plant Pathol. 22:51-60.

2. Dhingra, O. D., and Sinclair, J. B. 1985. Basic Plant Pathology Methods. 2nd ed. CRC Press, Boca Raton, FL.

3. Dill-Macky, R., and Jones, R. K. 2000. The effect of previous crop residues and tillage on Fusarium head blight of wheat. Plant Dis. 84:71-76.

4. Fernando, W. G. D., Miller, J. D., Seaman, W. L., Seifert, K., and Paulitz, T. C. 2000. Daily and seasonal dynamics of airborne spores of Fusarium graminearum and other Fusarium species sampled over wheat plots. Can. J. Bot. 78:497-505.

5. Francl, L., Shaner, G., Bergstrom, G., Gilbert, J., Pedersen, W., Dill-Macky, R., Sweets, L., Corwin, B., Jin, Y., Gallenberg, D., and 
Wiersma, J. 1999. Daily inoculum levels of Gibberella zeae on wheat spikes. Plant Dis. 83:662-666.

6. Gilbert, J., and Tekauz, A. 2000. Review: Recent developments in research on fusarium head blight of wheat in Canada. Can. J. Plant Pathol. 22:1-8.

7. Larson, C., Francl, L. J., and Friesen, T. 2001. Evaluation of the Burkard cyclonic spore sampler for collection efficiency of ascospores. Plant Dis. 85:1249-1252.

8. McMullen, M., Jones, R., and Gallenberg, D. 1997. Scab of wheat and barley: A reemerging disease of devastating impact. Plant Dis. 81:1340-1348.

9. Nelson, P. E., Toussoun, T. A., and Marasas, W. F. O. 1983. Fusarium Species, an Illustrated Manual for Identification. Pennsylvania State University, State College.

10. Oke, T. R. 1987. Boundary Layer Climates. 2nd ed. University Press, Cambridge, UK.

11. Paulitz, T. C. 1996. Diurnal release of ascospores by Gibberella zeae in inoculated wheat plots. Plant Dis. 80:674-678.

12. Pinkerton, J. N., Stone, J. K., Nelson, S. J., and Johnson, K. B. 1995. Infection of European hazelnut by Anisogramma anomala: Ascospore adhesion, mode of penetration of immature shoots, and host response. Phytopathology 85:1260-1268.

13. Ries, E. M. 1990. Effects of rain and relative humidity on the release of ascospores and on the infection of wheat heads by Gibberella zeae. Fitopatol. Bras. 15:339-343.

14. Salas, B., Steffenson, B. J., Casper, H. H., Tacke, B., Prom, L. K., Fetch, T. G., Jr., and Schwarz, P. B. 1999. Fusarium species pathogenic to barley and their associated mycotoxins. Plant Dis. 83:667-674

15. Stack, R. 1989. A comparison of the inoculum potential of ascospores and conidia of $\mathrm{Gib}$ berella zeae. Can. J. Plant Pathol. 11:137-142.

16. Stack, R. W., and McMullen, M. P. 1985. Head blighting potential of Fusarium species associated with spring wheat heads. Can. J. Plant Pathol. 7:79-82.
17. Sutton, J. C. 1982. Epidemiology of wheat head blight and maize ear rot caused by Fusa rium graminearum. Can. J. Plant Pathol. 4:195-209.

18. Tschanz, A. T., Horst, R. K., and Nelson, P. E. 1976. The effect of environment on sexual reproduction of Gibberella zeae. Mycologia 68:327-340.

19. Wiese, M. V. 1987. Compendium of Wheat Diseases. 2nd ed. American Phytopathological Society, St. Paul, MN.

20. Wilcoxson, R. D., Kommedahl, T., Ozmon, E. A., and Windels, C. E. 1988. Occurrence of Fusarium species in scabby wheat from Minnesota and their pathogenicity to wheat. Phytopathology 78:586-589.

21. Windels, C. E., and Kommedahl, T. 1984 Late-season colonization and survival of Fusarium graminearum Group II in cornstalks in Minnesota. Plant Dis. 68:791-793.

22. Zadoks, J. C., Chang, T. T., and Konzak, C. F. 1974. A decimal code for the growth stages of cereals. Weed Res. 14:415-421. 